\title{
Heat Transfer in Human Skin Exposed to Radiation from Forest Fire Taking Into Account Moisture Evaporation
}

\author{
Nikolay Poptsov ${ }^{1}$, Nikolay Baranovskiy ${ }^{1, *}$ \\ ${ }^{1}$ National Research Tomsk Polytechnic University, 634050 Tomsk, Russia
}

\begin{abstract}
Thermal radiation is one of the damaging factors of forest fire. As a result of exposure to radiant heat flow, thermal damage of the human skin is possible. A layer of skin is considered with effective thermophysical characteristics. Thin layer of sweat excretion situated on top of the skin. A mathematical model of heat transfer in the system of "skin-excretion" is developed taking into account evaporation of moisture. Typical simulation results are presented.
\end{abstract}

\section{Introduction}

The problem of the damaging factor impact of the forest fire on living organisms has recently become relevant. One of these factors is radiation from a forest fire. Thermal damage can occurs as a result of exposure to radiant heat flux on the skin [1].

Over the past decade, the scope of intensive research and application of heat exchange phenomena has greatly expanded. It includes both the leading directions of technology (chemical technology, metallurgy, construction, oil production, engineering, agricultural technology) and the basic natural sciences (biology, geology, atmospheric and ocean physics). At present time theoretical research of heat exchange processes is largely based on their numerical simulation using computers. This became possible due to significant progress in the development of computational methods to solve partial differential equations and increasing the performance of up-to-date computers.

The goal of the present work is to numerically study the thermal effect on the skin of radiation from forest fires taking into account moisture evaporation. To achieve this goal, the effect of heat radiation on the human skin near the fire is studied.

\section{Mathematical Setting-Up}

The skin is a complex structure with its own peculiarities in various parts of the body. It consists of three layers (Fig. 1) - epidermis, dermis and subcutaneous tissue (hypodermis) [1].

\footnotetext{
* Corresponding author: firedanger@tpu.ru
} 
The epidermis includes mostly dead cells that act as a protective barrier against moisture, ultraviolet radiation and high temperatures [2]. Sweat glands pass through the epidermis. The epidermis and dermis have a thickness of about 1-2 mm. These two layers are subcutaneous tissue (hypoderma), which contains sweat glands and large blood vessels, allowing the skin to adapt to local heating or cooling, but only within certain limits [3].

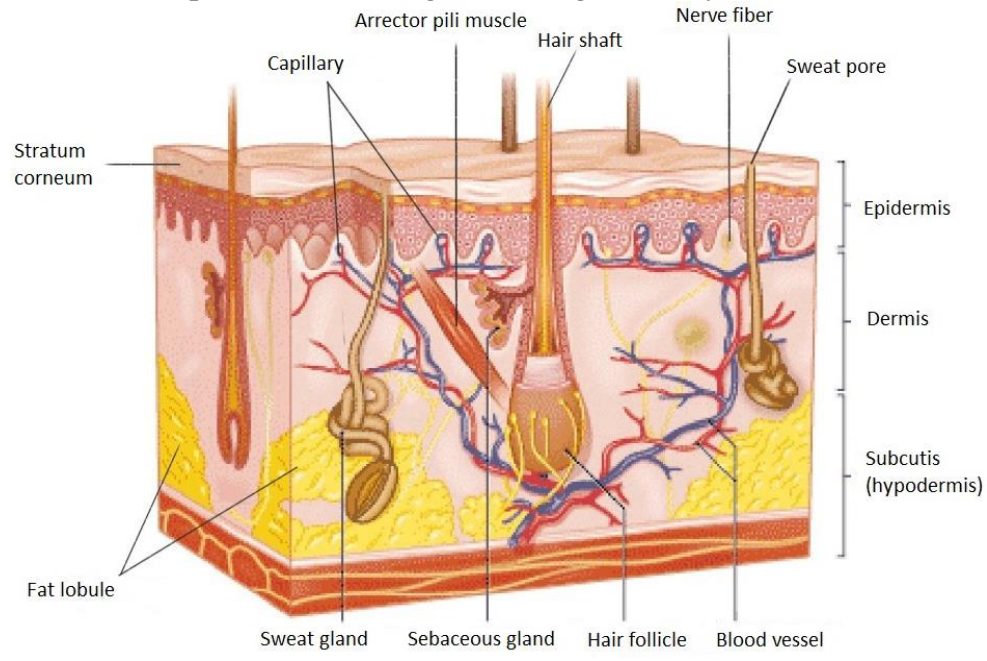

Fig. 1. Structure of the skin.

It is assumed that the examined area of the skin is affected by convective and radiant heat flux from the forest fire front. Thermophysical characteristics do not depend on temperature. The monolithic structure of the skin is considered. The heat transfer is leaded within the skin by conduction. Skin is considered as one layer with effective thermophysical characteristics.

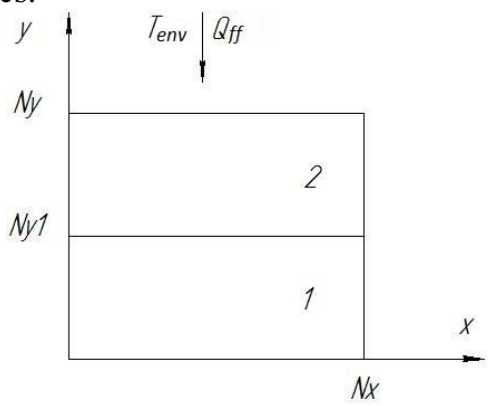

Fig.2. Geometry of the solution area: 1 - skin; 2 - sweat layer.

The geometry of the solution area is shown in Fig. 2. Heat transfer is described by nonstationary differential heat equations with the corresponding initial and boundary conditions:

$$
c_{1} \rho_{1} \frac{\partial T_{1}}{\partial t}=\lambda_{1}\left(\frac{\partial^{2} T_{1}}{\partial x^{2}}+\frac{\partial^{2} T_{1}}{\partial y^{2}}\right)
$$




$$
c_{2} \rho_{2} \frac{\partial T_{2}}{\partial t}=\lambda_{2}\left(\frac{\partial^{2} T_{2}}{\partial x^{2}}+\frac{\partial^{2} T_{2}}{\partial y^{2}}\right),
$$

Initial conditions :

$$
t=0, T_{i}=T_{i 0}
$$

Boundary conditions :

$$
\begin{gathered}
x=0, \lambda_{i} \frac{\partial T}{\partial x}=0 \\
x=N x, \lambda_{i} \frac{\partial T}{\partial x}=0, \\
y=N y,-\lambda_{2} \frac{\partial T}{\partial y}=\alpha\left(T_{e n v}-T\right)+\varepsilon \sigma\left(T_{e n v}^{4}-T^{4}\right)-Q_{e v} \cdot W_{e v}+Q_{f f} \\
y=N y_{1}, \lambda_{1} \frac{\partial T_{1}}{\partial y}=\lambda_{2} \frac{\partial T_{2}}{\partial y}, T_{1}=T_{2}, \\
y=0, \lambda_{1} \frac{\partial T_{1}}{\partial y}=0, \\
A\left(P_{0} \cdot \exp \left(-\frac{E}{R T}\right)-P_{a t m}\right) \\
W_{e v}=\frac{\sqrt{\frac{2 \pi R T}{M}}}{\sqrt{2 \pi}}
\end{gathered}
$$

Where $T_{i}, \rho_{i}, c_{i}, \lambda_{i}-$ temperature, density, heat capacity, heat conduction coefficient ( $i=1$ - sweat layer, 2 - skin layer). $\mathrm{x}, \mathrm{y}$ - spatial coordinates. $\mathrm{t}$ - time. $\alpha$ - heat transfer coefficient. $\mathrm{Q}_{\mathrm{ev}}-$ heat effect of evaporation. $\mathrm{Q}_{\mathrm{ff}}-$ heat flux from forest fire. $\varepsilon-$ emissivity coefficient. $\sigma-$ Stefan-Boltzmann constant. $\mathrm{W}_{\mathrm{ev}}-$ evaporation mass rate. A accommodation coefficient. $\mathrm{P}_{0}-$ pre-exponent factor. $\mathrm{E}-$ activation energy. $\mathrm{P}_{\mathrm{atm}}-$ atmospheric pressure. $\mathrm{R}$ - universal gas constant. $\mathrm{M}$ - molecular weight.

\section{Results and Discussion}

Partial differential equations of the parabolic type are used for the mathematical description of the heat transfer process. The numerical implementation is carried out using the finitedifference method [4,5]. As a result, temperature distributions were obtained in the "skinexcretion" structure. Numerical simulation was carried out for the following scenario. A person deprived of personal protective equipment situated at some distance from the front 
of a forest fire. Heat releases as a result of combustion of forest combustible materials. Heat transfer occurs to the human body through radiation [6].

For definiteness, the effect of radiant heat flux on a specific part of the body is considered (namely, the frontal part of the human hand palm [7]). Table 1 shows the initial data.

Table 1. Initial data.

\begin{tabular}{|l|c|}
\hline Layer & Skin and sweat \\
\hline Temperature of the environmnet, & 900 \\
$T_{e n v},{ }^{\circ} \mathrm{C}$ & 36,6 \\
\hline Initial temperature, $T_{0},{ }^{\circ} \mathrm{C}$ & 1 \\
\hline Layers thickness, $\mathrm{mm}$ & \multirow{2}{*}{${ }^{\circ}$} \\
\hline
\end{tabular}

According to the obtained results it was found that when the sweat layer evaporates at the time, the surface temperature of the skin reaches $54^{\circ} \mathrm{C}$. Thickness of the heating is small in comparison with the dimensions of the layer under study. Comparative analysis allows to draw a conclusion about the correct operation of the presented software implementations for the mathematical model which describes heat transfer in the skin structure under the influence of radiant heat flux from the forest fire front [6].

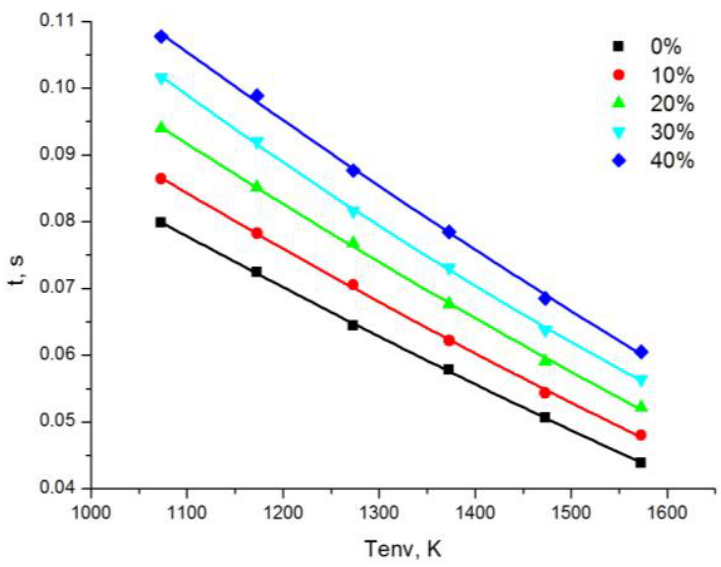

Fig. 3. Dependence of the pain threshold when the sweat evaporates from the skin surface from the ambient temperature at different salt content.

Analysis of the dependences in Fig. 3, 4 allows us to conclude that increasing the mass content of salt in the sweat leads to increase of evaporation time. The onset of the pain threshold increases the more caused by the lower ambient temperature. The pain threshold time ranges from $0.04 \mathrm{~s}$ (ambient temperature of about $1573 \mathrm{~K}$ and mass concentration of the salt in the sweat of $0 \%$ ) to $0.1 \mathrm{~s}$ (ambient temperature of about $1073 \mathrm{~K}$ and mass concentration of the salt in the sweat of about $40 \%$ ). The time for complete moisture evaporation varies from $0.05 \mathrm{~s}$ (ambient temperature of about $1573 \mathrm{~K}$ and mass concentration of the salt in the sweat of $0 \%$ ) to $0.15 \mathrm{~s} \mathrm{(ambient} \mathrm{temperature} \mathrm{of} \mathrm{about} 473 \mathrm{~K}$ and mass concentration of salt in the sweat of $40 \%$ ). The pain threshold times and complete evaporation grow with increasing concentration of salt in sweat. 


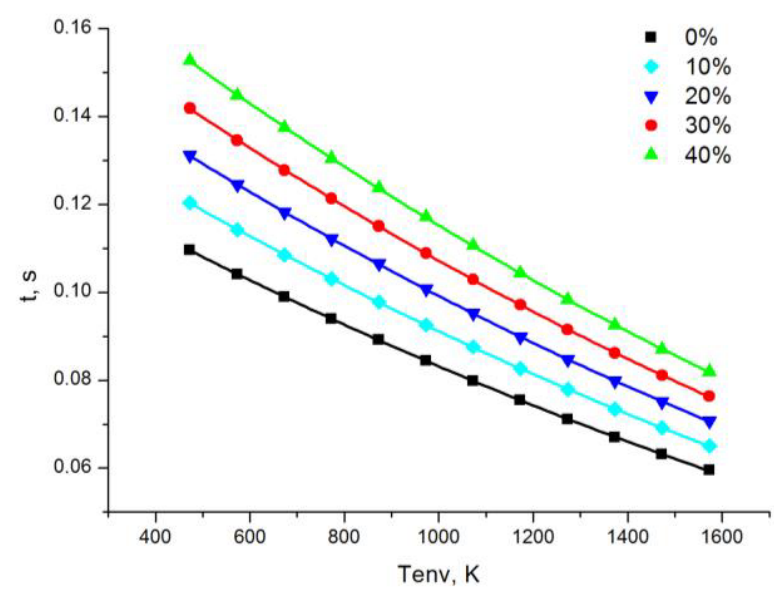

Fig. 4. Dependences of time on salt content for evaporation of whole sweat layer.

\section{Conclusion}

Mathematical model of heat transfer in the skin structure has been developed. Algorithm and program implementation of the skin warming has been carried out taking into account radiation and convection with evaporation of the sweat layer in a high temperature environment. The software components have been created to simulate the heat transfer in the skin structure. These might be applied to the development of a new generation medical information systems $[8,9]$ and also for integration with GIS of forest fire hazard prediction $[10,11]$ based on deterministic-probabilistic approach [12].

Authors are glad to express thanks to Dr. Semen V. Syrodoy for useful comments and discussion of present work.

Work is impelemnted within the project N 7538.2016.8 (Granted by President of Russian Federation within Leading Scientific Schools Program)

\section{References}

1. J.T. Whitton, J.D. Everall, Br. J. Dermatol. 89 (1973)

2. F. Xu, T.J. Lu, K.A. Seffen, Acta Mechanika Sinica, 24 (2008)

3. A.E. Pushkareva Laser selective heating of skin tissue elements: PhD thesis. Saint petersburg: ITMO University. (2006) [In Russian]

4. E.N. Valendik, I.V. Kosov, Siberian Ecological Journal, 4 (2008) [In Russian]

5. D.V. Korobkina, N.V. Baranovskiy, MATEC Web Conf. 19 (2014)

6. A.A. Samarskii, P.N. Vabishchevich, Computational Heat Transfer. Vol. 1. Mathematical Modelling (Chichester, Wiley, 1995)

7. A.A. Samarskii, P.N. Vabishchevich, Computational Heat Transfer. Vol. 2. The Finite Difference Method (Chichester, Wiley, 1995)

8. S. Petter, A. Fruhling, Int. J. Medical Inf., 80 (2011)

9. N. Bricon-Souf, C. Verdier, A. Flory, M.C. Jaulent, IRBM, 34 (2013)

10. E.P. Yankovich, N.V. Baranovskiy, SGEM, 1, 2 (2014)

11. E.P. Yankovich, N.V. Baranovskiy, K.S. Yankovich, 2014 9th International Forum on Strategic Technology, IFOST (2014)

12. N.V. Baranovskiy, J. Autom. Inf. Sci. 47 (2015) 